\title{
A COMUNIDADE DOS QUE ESCREVEM A COMUNIDADE
}

THE COMMUNITY OF THOS WHO

WRITE THE COMMUNITY

\section{Janaina Rocha de Paula Luis Fernando Balby}

\author{
Universidade Federal de Minas Gerais \\ Belo Horizonte - Brasil
}

\section{Resumo}

Este artigo pretende investigar o pensamento da comunidade a partir dos livros: Comunidade inconfessável, de Maurice Blanchot e Comunidade inoperada, de JeanLuc Nancy. Esses autores nos oferecem um aparato teórico que nos permite pensar a comunidade como um movimento incessante e ininterrupto, uma exigência inédita que ainda está para ser descoberta. Partindo da experiência literária de três autores que se distanciam no tempo, mas se aproximam na escrita - Nietzsche, Bataille e Llansol -, abordamos o pensamento da comunidade como algo que se inscreve no campo da abertura de sentido, num domínio, portanto, que é mais da literatura do que da filosofia. Isso pelo fato de que seu o aparecimento requer, na mesma medida, a sua criação.

Palavras-chave: Comunidade, Experiência, Singularidade, Textualidade.

\section{Abstract}

This article intends to investigate the thought of the community from Jean-Luc Nancy's 'The inconfessible community', and Maurice Blanchot's 'The inoperable community'. These authors offer a theoretical suport that allows us to think 'the community' as an incessant and uninterrupted movement, an unprecedented requirement that is yet to be discovered. Starting from the literary experience of three authors who are distant in time, but close in terms of writing - Nietzsche, Bataille and Llansol-, we approach the thought of the community as something that is inscribed in the field of the opening of meaning, in a domain, therefore, that

\section{Résumé}

Cet article se penche sur la pensée de la communauté à partir des livres suivants: La communauté inavouable de Maurice Blanchot et La communauté désoeuvrée de Jean-Luc Nancy. Ces auteurs offrent un apport théorique qui nous permet de penser la communauté en tant que mouvement continu et ininterrompu, une exigence inédite qui est encore à découvrir. Partant sur l'expérience littéraire de trois auteurs si éloignés par le temps mais si proches par leurs écrits - Nietzsche, Bataille et Llansol, nous aborderons la pensée de la communauté en tant qu'élément qui s'inscrit dans le champ d'ouverture de sens, dans un domaine donc qui appartient à la litterature plutôt qu’à la philosophie. 
is more of literature than of philosophy. This is to the extension to the fact that the community existence requires, in the same measure, its creation.

Keywords: Community, Experience, Singularity, Textuality.
Cela est dû au fait que son apparition demande, dans une mesure égale, sa création.

Mots-clés: Communauté, Expérience, Singularité, Textualité.

Introdução

Gestos para os três, gestos para cada um [...] A sua resposta é: comunidade de figuras. (LLANSOL, 2004, p. 72)

A comunidade, pensada como um problema teórico, é uma discussão relativamente recente. Ao tomarmos por base o conceito que emerge da justaposição dos textos de Jean-Luc Nancy (A comunidade inoperada) e Maurice Blanchot (A comunidade inconfessável), descobrimos um conceito - sempre em vias de escapar - que, de forma paradoxal, se destaca da dicotomia que polarizou os debates nos campos da filosofia e da história do século passado, ora em torno da defesa da supremacia de uma cultura do indivíduo, ora a favor da possibilidade do comunismo hegemônico. Nancy e Blachot nos deram o aparato teórico para que pudéssemos propor a discussão da questão da comunidade a partir de outros termos e apontando para outros fins.

No contexto histórico que atravessamos, em que a temática do indivíduo se radicalizou ao ponto do narcisismo patológico, delineando consequências políticas e ambientais alarmantes para o futuro próximo, o mais importante é que esse novo aparato teórico fornece condiçóes de situarmos o pensamento da comunidade como uma crítica ao projeto filosófico e histórico da cultura do indivíduo. "O individualismo", diz Nancy, "é um atomismo inconsequente que esquece que a questão do átomo é aquela de um mundo" (NANCY, 2016, p. 30). E é por isso que concluímos que uma nova linguagem conceitual, que nos dê meios para pensarmos uma crítica consistente ao individualismo, entendido como sendo a moderna cultura do indivíduo, carrega o germe para desdobramentos e transformaçôes políticas e éticas bastante expressivas.

É evidente que o alcance dessa crítica foge ao escopo deste artigo. No entanto, não poderíamos deixar de destacar como significativo o fato de que o conceito de comunidade, tal como elaborado por Nancy e Blanchot, que emerge sobretudo do terreno literário, tenha tamanho potencial crítico e político. Do ponto de vista da criação, a literatura é muitas vezes confundida, em seus processos, com os mitos do gênio, do "intelectual de gabinete", do indivíduo 
solitário e sublime, ou - mais modernamente -, do escritor-publicitário. Do ponto de vista do público e da recepção, a literatura é assimilada ora como entretenimento, ora como matéria e domínio para determinado círculo de intelectualização. Nesses meios é que a própria literatura se deixa contaminar pela marca do empreendimento individual, em que se vê esvaziada de suas potencialidades transformadoras, e, mais do que isso, de seu status de objeto que serve, antes de tudo, para estabelecer - ou criar - a comunicação ${ }^{1}$. Georges Bataille foi sensível a esse alcance (necessário) da literatura:

Nada há de humano que não exija a comunidade daqueles que o querem. Aquilo que vai longe exige esforços conjugados, que ao menos deem continuidade um ao outro, sem se deter no possível de um só. Se tiver cortado os laços à sua volta, a solidão de um homem é um erro. Uma vida não é mais do que um elo numa corrente. Quero que outros continuem a experiência que antes de mim outros começaram, que se devotem como eu, como outros antes de mim, ao meu desafio: ir até o limite do possivel. (BATAILLE, 2017, p. 44)

Um importante aspecto da forma do pensamento de Bataille se expressa aqui: o de que nela o método de aproximação do objeto se confunde com o próprio objeto, ou, dito de outra maneira, a escrita de Bataille opera a fusão do sujeito com seu objeto. A comunidade, definida por ele como a transposição possível do limite de um (ser) só, não é apenas o objeto de seu pensamento, ela é também o meio para alcançar esse objeto.

Nesse sentido, Bataille é sem dúvida aquele que fez, pela primeira vez ou fez de maneira mais incisiva, a experiência moderna da comunidade: nem obra a ser produzida, nem comunhão perdida, mas o espaço mesmo, o espaçamento da experiência do fora, do fora de si. (NANCY, 2016, p. 48)

É o espaço da relação que é recuperado pelo pensamento de Bataille, ponto em que ele se afasta decididamente da metafísica do ser (individual, na medida em que absoluto e encerrado em torno de si mesmo) e do sujeito, para pensar o que há no entre: nas formas possíveis de acessar e sustentarainda que de maneira transitória - a comunidade, a partilha dos seres. Mas, na medida em que a comunidade é definida como a experiência do espaço do "fora de si", é impossível que ela se constitua pela matéria daquilo que há em comum para cada indivíduo. A comunidade pensada nesses termos não é, ao contrário do que poderia parecer, o espaço da projeção do privado para

1 Ainda, neste ponto, não nos aprofundaremos na discussão de que tipo de comunicação se trata aqui, ou melhor dizendo, em que nível essa comunicação se dá. Por ora basta dizer que não estamos falando, é evidente, das formas assumidas pela comunicação de massas, tampouco dos veículos para comunicaçáo entre indivíduos. 
o público, mas o espaço constituído pelo que cada sujeito possui de mais radicalmente diferente de si, o espaço, por assim dizer, da não-identidade.

Disso decorre a dificuldade de pensarmos a comunidade como um conceito. Pois se ela existe como um objeto, trata-se sempre de um objeto em vias de se perder, sobre o qual nunca se chega a ter um domínio. Isso não significa que seus efeitos sejam tão abstratos quanto a sua definiçáo. A experiência do amor (dos amantes) traduz, em certo sentido, esse entendimento que procuramos ter da comunidade ${ }^{2}$, assim como a experiência literária, quando essa se faz comunicar por meio da experiência da leitura, ou quando se materializa na forma do texto.

Ainda a respeito desta dificuldade, Blanchot escreve:

[...] esse paradoxo confirma talvez a extravagância daquilo que se busca designar pelo nome de comunidade. [...] comunidade tradicional [...] nos é imposta sem que nossa liberdade decida: é a socialidade de fato, ou ainda a glorificação da terra, do sangue, até mesmo da raça? [...] essa escolha é livre? $\mathrm{Ou}$, pelo menos, essa liberdade é suficiente para exprimir, para afirmar a partilha que é a verdade dessa comunidade? (BLANCHOT, 2013, p. 65)

Eis o ponto em o pensamento da comunidade diferencia-se tanto do comunismo - entendido como o ímpeto violento de suplantar qualquer singularidade -, quanto da noção de sociedade - que nunca é mais do que o aglomerado de unidades atômicas fechadas em si e isoladas umas das outras. Em A comunidade inoperada, Nancy deixa claro que, a despeito de sua exigência, a experiência da comunidade nunca se manifestou, nem do ponto de vista histórico-material, nem sequer como preocupação dos grandes sistemas filosóficos. "É nesse sentido", ele diz, "que a exigência da comunidade é ainda inédita, que ela ainda deve ser descoberta e pensada". (NANCY, 2016, p. 53). Por ser inaudito, o pensamento da comunidade, como se vê, para ambos os escritores, mas também para outros como Nietzsche, Bataille e Maria Gabriela Llansol, se inscreve no campo da abertura do sentido, num domínio, portanto, que é mais da literatura do que da filosofia. Isso pelo fato de que seu o aparecimento requer, na mesma medida, a sua criação.

Tomemos, então, esses três autores: Nietzche, Bataille e Llansol. Separados pelo tempo de uma vida, reunidos pelo tempo de uma escrita. Reunilos aqui, tendo como eco os termos: comunidade inconfessável e comunidade inoperada, de Blanchot e Nancy, talvez nos permita tocar no ponto em que a comunidade, assim como a literatura, abre, no gesto de uma leitura amante, o devir: o devir de uma comunidade literária, ou seja, daqueles que escrevem a comunidade.

$2 \mathrm{O}$ próprio Bataille nomeia a experiência da comunidade como sendo análoga àquela que ele definiu como erotismo (ver: Bataille. O erotismo, 1987). 
"Dizer sim, como diz sim o céu aberto" (NIETZSCHE, 1998, p. 228). O sim de Nietzsche, esse que abre o céu e faz dançar uma estrela, descrito por ele mesmo como sendo a "vontade de potência", se deixa ressoar numa linguagem inventiva e criadora. Assim falou Zaratustra nos parece o exemplo mais marcante de um certo ímpeto, muitas vezes desesperado, e que pode facilmente ser traduzido como uma "vontade de comunidade":

Mil caminhos existem, que ainda não foram palmilhados, mil saúdes e ocultas ilhas da vida. Ainda não esgotados nem descobertos continuam o homem e a terra dos homens. Quedai-vos vigilantes e à escuta, ó solitários! Chegam ventos, do futuro, com misteriosos bater de asas; e trazem boa nova aos ouvidos finos. Vós, os solitários de hoje, os segregados, sereis, algum dia, um povo; de vós, que vos elegestes a vós mesmos, deverá nascer um novo eleito; e, dele - o super-homem. (NIETZSCHE, 1998, p. 91)

O que há de inusitado - ou mesmo de propriamente insano - na experiência de Nietzsche é que em seu caso tratava-se de um espírito único, firmemente agarrado ao que havia de mais radical na vivência de sua própria singularidade. Ao mesmo tempo, por outro lado, nutrindo desprezo por seus pares e contemporâneos, Nietzsche jamais abandonou a esperança de que sua escrita ecoasse e encontrasse ouvidos num outro tempo, no tempo futuro. A escrita sustentava o seu desejo de singularidade, ao mesmo tempo em que avançava para o devir de uma comunidade. Nesse tempo futuro, nesse por vir aberto pelo sim de uma escrita, ele avançava em direção àquilo que Blanchot designará como sendo "a comunidade dos que não têm comunidade". Não seria demais concluir que o desejo da escrita que o mobilizava se manifestasse como uma saída para o impasse entre dois pontos aparentemente contraditórios, mas igualmente importantes: a necessidade de sustentar uma singularidade $e$ a vontade de comunidade. Não por acaso, a forma da linguagem de Nietzsche é comumente a do paradoxo.

Parece-nos, em grande medida, que a apropriação insidiosa do texto de Nietzsche como justificativa da ideologia fascista se deve à maneira enérgica com que ele se levantava contra os princípios ainda em voga de um humanismo iluminista e kantiano, pautado pelo princípio do bom uso da razão e da liberdade individuais. Ora, Nietzsche repudiava com veemência a figura do indivíduo burguês, descartava a doutrina do livre arbítrio como possível parâmetro ético de ação, desautorizava também uma concepção de justiça fundamentada na culpa e, portanto, na punição individual, e se enojava da emergente palavra 'democracia', que trazia consigo os princípios iluministas da cidadania burguesa. Mas tudo se complica ao ponto do paradoxo 
quando, pelas palavras de Zaratustra, as ideologias da igualdade são também violentamente atacadas:

Meus amigos, não quero ser misturado e confundido com ninguém. [...] Não quero ser misturado e confundido com esses pregadores da igualdade. Porque, a mim, assim fala a justiça: "os homens não são iguais". E, tampouco, o devem tornar-se! Que seria o meu amor pelo super-homem, se falasse de outro modo? (NIETZSCHE, 1998, p. 114)

Não obstante, eu caminho com os meus pensamentos sobre suas cabeças; e, mesmo se quisesse caminhar com minhas próprias falhas, estaria ainda caminhando sobre eles e suas cabeças. Porque os homens não são iguais: assim fala a justiça. E aquilo que eu quero não têm, eles, o direito do querer! (NIETZSCHE, 1998, p. 138)

É verdade que Nietzsche nunca encontrou uma palavra para nomear isso que não se delimita a partir desses dois polos de referência: ou o da sociedade massificada de individualidades, ou o do totalitarismo homogeneizante. Em seu desespero em relação aos impasses e ao ímpeto de expressar uma noção mal formulada de 'singularidade', Nietzsche se precipita em direção a uma outra saída: a da incessante escrita. Com efeito, em algum momento tardio de sua produção, poucos anos antes de seu colapso, ele abandona o ofício de filósofo profissional (com o qual, de fato, raramente se identificara), para assumir (inconfessado) o de escritor. $\mathrm{E}$ isso náo porque Nietzsche tivesse inclinaçóes estéticas para a ficção, mas sim porque compreendia a necessidade que tinha da linguagem - acima de todas as coisas -, para sustentar e afirmar uma singularidade, ou ainda (com uma palavra de seu léxico), para dar forma à sua "vontade". Ecce homo é a obra que traduz, na forma do desespero, tal ímpeto de Nietzsche - fadado, mais uma vez, à incompreensão.

Nancy e Blanchot avançam, nos livros citados, com o conceito de singularidade, tomando como ponto de partida os textos de Bataille que, por sua vez, muito se aproximavam do desespero lúcido de Nietzsche. Nancy pontua que, assim como Nietzsche, Bataille não havia encontrado para o termo a sua exata definição, se valendo, portanto, indevidamente da palavra "sujeito" para se referir a um outro tipo de experiência:

Decerto, a palavra "sujeito" só poderia ser em Bataille uma palavra. E, sem dúvida, o seu conceito não foi nem a noção ordinária da "subjetividade" [...]. A experiência interior definiu, ao contrário: "si mesmo" não é o sujeito se isolando do mundo, mas um lugar de comunicação, de fusão do sujeito e do objeto". (NANCY, 2016, p.54) 
Eis aqui uma possível definição de "singularidade"': lugar de comunicação, de fusão do sujeito com o objeto. A importância dessa definição é que ela já nos dá uma das bases para a crítica à cultura do individuo. Ora, de uma perspectiva individual, tudo no mundo é objeto, na medida em que as coisas e outras individualidades existem para cumprir uma determinada função para o indivíduo. Ele usufrui das coisas e de outras individualidades para sua saciedade pessoal; na sequência, ele as descarta (reiniciando seu ciclo de consumo).

Contrapondo-se a essa perspectiva, Blanchot, na aproximaçáo com os textos de Bataille, situou, em seus escritos, o princípio que define o ser singular:

Repito, para Bataille, a interrogação: por que "comunidade"? A resposta é dada de modo bastante claro: "Na base de cada ser existe um princípio de insuficiência..." (princípio de incompletude). É um princípio, notemo-lo bem, isso que comanda e ordena a possibilidade de um ser. Donde resulta que essa falta por princípio não anda ao lado de uma necessidade de completude. [...] A consciência da insuficiência vem de sua própria colocação em questão, a qual tem necessidade do outro ou de um outro para ser efetuada. Sozinho, o ser se fecha, adormece e se tranquiliza. [...] O ser busca, não ser reconhecido, mas ser contestado: ele vai, para existir, em direção ao outro que o contesta e por vezes o nega [...] (está aí a origem de sua consciência) da impossibilidade de ser ele mesmo, de insistir [...] como indivíduo separado [...]. (BLANCHOT, 2013, p.17)

Seguindo o pensamento de Blanchot, "a insuficiência não se conclui a partir de um modelo de suficiência. Ela não busca aquilo que poria um fim a isso, mas, antes, o excesso de uma falta que se aprofunda à medida que ele vá se preenchendo" (BLANCHOT, 2013, p.20). O que nos chama a atenção nessa definição do ser singular, a partir do princípio de incompletude, é que aos poucos ela delineia uma saída para o aparente paradoxo entre o aprofundar-se na vida íntima, na "experiência interior" (Bataille), ou na "solidão essencial" (Blanchot), e a necessidade de comunidade. O ser é o ser na medida em que vive sua incompletude e aprofunda-se na angustiante experiência de sua insuficiência. A completude pressuposta pela relação sujeito-objeto é, nesse sentido, a negaçáo do ser, fundamento patológico de toda neurose individual. O outro elemento estranho dessa definiçẫo é a expressão utilizada por Blanchot: "excesso de uma falta que se aprofunda". Essa expressão, como paradoxo, se inscreve no campo da experiência e da abertura do sentido, sugerindo uma estranha relação entre angústia e conhecimento, ou entre conhecimento e uma vivência cada vez mais profunda no não-saber.

"No" "NADA", ou em nada - na soberania - o ser "fora de si"; ele é numa exterioridade impossível de se alcançar, ou talvez se deveria dizer que 
ele é a partir dessa exterioridade, que é um fora que não pode se relacionar, mas com o qual mantém uma relação essencial e incomensurável. Essa relação ordena por sua vez o ser singular. É por isso que "a experiência interior" da qual fala Bataille não tem nada de "interior", nem de "subjetiva", mas é indissociável da experiência dessa relação com o fora incomensurável. A essa relação, somente a comunidade provê seu espaço ou seu ritmo. (NANCY, 2016, p. 47-48)

Conforme as definiçóes de Blanchot e Nancy, a singularidade é da ordem do movimento incessante, do devir, do "eterno retorno da diferença"3. Não há contradição em dizer que a singularidade, inscrita pelo movimento da mão que escreve, pode vir a se confirmar, a se estabelecer na forma-livro, na experiência literária. Mas aqui estaremos no campo da linguagem criada por e para as não-identidades, como empreendimento destinado à abertura do sentido. Afastamo-nos assim do domínio das obras para adentrarmos no domínio daquilo que Blanchot chamou de déseuvrement. "Ela não é", nos diz Nancy, aproximando-se bastante daquilo que Barthes definiria também como sendo o campo metodológico do 'Texto', "uma obra resultante de uma operação. Não há processo de 'singularização' e a singularidade não é extraída, nem produzida, nem derivada. [...] É um 'fundo' sem fundo, [...] no sentido de ser feito apenas da rede, do entrelaçamento e da partilha de singularidades" (NANCY, 2016, p. 59).

\section{A partilha, (há) a literatura}

É verdade, por outro lado, que a literatura jamais se esgota no gesto mecânico da mão que escreve. Que este movimento venha, como no caso de Nietzsche, do ímpeto de estruturar, por meio da linguagem, o ser singular, isso nos traz de volta para a discussáo da forma, para que possamos pensar que a necessidade da afirmaçáo singular está entrelaçada, ao ponto de, na prática, ser indissociável, com a "vontade de comunicar". E assim poderíamos lançar como questáo relevante não exatamente aquela que indaga o valor daquilo que é comunicado, mas sim a respeito do que é que de fato se partilha quando falamos em literatura?

Ao nos detemos na forma da linguagem de Zaratustra, constatamos que, caso a intenção de Nietzsche tivesse sido a de estabelecer a comunicação, em um sentido convencional, ela fracassa. Mas não há nada de convencional nesse texto que chega a nós por meio de uma linguagem obscura, deliberadamente enigmática, em que as palavras não nos comunicam e, por mais que as tentemos decifrar, o sentido nos escapa. E, no entanto, ali mesmo onde ele fracassa, ele comunica. Tudo no texto "comunica por incompreensão. Nada está em

3 Noção trabalhada por Deleuze em Nietzsche e a filosofia. 
nada, apesar das múltiplas implicaçóes das formas entre si, o conhecimento mútuo e, sobretudo o reconhecimento, não é um dado inicial, dado à partida" (LLANSOL, 1994, p. 142).

Novos caminhos sigo, uma nova fala me empolga: como todos os criadores, cansei-me das velhas línguas. Não quer mais, o meu espírito, caminhar com solas gastas. Lentos demais, para mim, correm todos os discursos: vou pular para o teu carro, furacão! E, mesmo a ti, quero fustigar-te com a minha maldade! Com um grito e uma explosão de júbilo, quero navegar por amplos mares, até encontrar as ilhas bem-aventuradas onde vivem os meus amigos. (NIETZSCHE, 1998, p. 98)

Ao recusar as velhas línguas e todos os discursos, movendo-se em direção a uma "nova fala", Nietzsche demonstra que seu projeto passava pela criação, por meio de Zaratustra, de uma nova linguagem. Uma língua que lhe daria acesso a mares mais amplos e ao encontro com os amigos. Quanto ao que possa haver de estranho ou de obscuro nessa nova linguagem, isso se deve, precisamente, ao fato de que nesse ponto Nietzsche sacrifica o terreno das linguagens conhecidas (dos discursos) e se empenha na tentativa de estabelecer comunicação, mas a partir do que ainda não havia sido experimentado. É nesse ponto que ele faz literatura: no espaço mesmo de uma singularidade em torno da qual reuniria, em diferentes tempos, os "absolutamente sós" (LLANSOL, 1994, p. 54).

Saímos do domínio em que o escritor possui o controle do alcance de seus significantes. É como se a literatura - ao menos em casos de escritas tão radicais, como as de Nietzsche, Bataille e Llansol - se oferecesse não só como o meio, mas igualmente como a forma de sustentar a relação com o desconhecido. É para o desconhecido mesmo que essas formas literárias dirigem suas palavras: "aquele para quem escrevo", nos diz Blanchot, "é aquele que ninguém pode conhecer, ele é o desconhecido, e a relação com o desconhecido, mesmo que seja pela escritura, me expóe à morte ou à finitude [...]" (BLANCHOT, 2013, p. 39). Pensamos que essa noção de 'morte' que aparece nos textos de Blanchot e de Bataille, refere-se, com efeito, à morte do sujeito identitário, do ser absoluto e fechado, para quem a repetição dos mesmos significados serve para formatar uma imagem sempre estável de si, com a qual ele se identifica e, suspostamente, se tranquiliza.

Quando a comunicação é destinada não a formatar essas identidades, mas a reafirmar as singularidades e a diferença, ela parte da relação com o desconhecido que há na "experiência interior", porque o outro com quem se deseja estabelecer o encontro só pode ser, propriamente o outro na medida em que não é o igual a si mesmo. É esta dimensão de uma estranha partilha, colocada em cena pelo objeto literário, que nos interessa pensar a respeito: 
[...] a própria partilha - não é uma comunhão, nem uma apropriação do objeto, nem um reconhecimento de si, nem mesmo uma comunicaçáo, como a compreendemos, entre sujeitos. Mas esses seres singulares são eles mesmos constituídos pela partilha, eles se distribuem e se póem, ou mesmo se espaçam pela partilha que os fazem outros: [...] no êxtase da partilha: "comunicado" para não "comungar". Esses "lugares de comunicação" não são mais lugares de fusão. (NANCY, 2016, p. 55-56)

Estabelece-se, nestes casos, pela via da experiência literária, uma espécie de amizade com o desconhecido, aquilo que Blanchot chamará de "relação sem relação ou sem relação outra que o incomensurável", ou ainda "amizade [que] entra em jogo e a cada instante se perde". "Assim é, assim seria a amizade que descobre o desconhecido que somos nós mesmos, e o encontro de nossa própria solidão que precisamente nós não podemos ser sozinhos a provar [...]" (BLANCHOT, 2013, p. 40). Isso porque o ser sozinho cai, invariavelmente, no sentido (de um) absoluto.

É impossível não reconhecer, tanto nos escritos de Nietzsche quanto nos de Bataille, a conformação de uma linguagem que suporta um pesado elemento de violência. Nietzsche denominou seu método, em Crepúsculo dos ídolos, como o de "filosofar a marteladas". Bataille se valeu do conceito de "sacrifício" para explicar o movimento que, a seu ver, operava na literatura. No caso da literatura, Bataille entendia que se tratava de infligir uma violência ao significante. De nossa parte, quando dizemos que a literatura serve para estabelecer a comunicação (com o desconhecido e entre singularidades), nos valemos do conceito que, a partir daí, Nancy desdobrou:

Uso o termo "comunicação" como empregado por Bataille, ou seja, segundo o regime de uma violência feita à significação da palavra, tanto como o que ela indica, a subjetividade ou intersubjetividade, como o que denota a transmissão de uma mensagem e de um sentido. [...] Essas operaçóes implicam necessariamente uma reavaliação geral da comunicação na comunidade e da comunidade (da palavra, da literatura, da troca, da imagem etc.) [...]. (NANCY, 2016, p. 48)

A questão da escrita, como movimento de violência, nos leva ao entendimento da literatura como práxis do discurso que opera a abertura do sentido, fazendo disso um gesto incessante. No caso de Nietzsche, impressiona como seus textos chegam a nós e revelam uma estranha vivacidade e capacidade de se comunicarem com questóes de nosso tempo. Igualmente estranho é que tais textos nos levem a experimentar a presença singular de Nietzsche, mas jamais a do indivíduo Nietzsche, e nos provoquem à escrita. 
Viver um possível até o limite exige uma troca entre várias pessoas, assumindo-o como um fato que lhes é exterior e que não depende mais de nenhuma delas isoladamente. Do possível que propôs, Nietzsche não duvidou que sua existência exigisse uma comunidade. $\mathrm{O}$ desejo de uma comunidade o agitava incessantemente. Ele escreveu: "O cara a cara com um grande pensamento é intolerável. Procuro e chamo homens a quem possa comunicar esse pensamento sem que eles morram por isso". Ele procurou sem nunca encontrar uma "alma profunda o bastante". Teve de se resignar, dizer a si próprio: "Depois de um tamanho apelo, jorrado das profundezas da alma, não escutar o som de resposta alguma é uma experiência aterradora que pode fazer perecer o homem mais tenaz: isso me liberou de todos os laços com os homens vivos". Seu sofrimento se expressa em numerosas notas... (BATAILLE, 2017, p. 45)

Bataille foi particularmente sensível a essa nova forma de conceber o texto e a linguagem não como objetos, mas como presenças irredutíveis. Seu gesto de leitura de tais textos talvez possa ser entendido como o de uma "apropriação singular" do sentido em abertura. O resultado de tal partilha entre os escritores é um novo texto: Bataille escrevendo sua comunidade com Nietzsche: "Minha vida, em companhia de Nietzsche, é uma comunidade, meu livro é essa comunidade" (BATAILLE, 2017, p.46).

Isso nos leva a pensar que poderíamos propor o texto como a forma de uma comunidade em que não há comunhão possível entre os seres, mas uma estranha forma de comunicação em que uma solidão se entrelaça a outra. É esse o ponto, afinal, em que a solidão de Nietzsche torna-se menos solitária, ainda que projetada em direção à comunidade por vir: "Que se passa comigo?", perguntou a si mesmo. "Há qualquer coisa quente e viva que me reanima; deve achar-se na minha vizinhança. Já me sinto menos só: desconhecidos companheiros e irmãos vagueiam a meu redor, seu cálido respiro penetra-me a alma" (NIETZSCHE, 1998, p.270).

\section{Ao lado de outros ela escreve: O Livro das comunidades}

Desde a publicação de Da obra ao texto, de Roland Barthes, temos condições de pensar o texto "[...] à imagem de um organismo que cresce por expansão vital, por 'desenvolvimento" e, também, por meio da "metáfora da rede", como um entrelaçamento plural, matéria que é, ao mesmo tempo, múltipla e "irredutível, proveniente de substâncias e de planos heterogêneos, destacados”. É ainda curioso que Barthes conclua essa exposição com o pensamento de que "o Texto participa a seu modo de uma utopia social", já que é "o espaço em que nenhuma linguagem leva vantagem sobre a outra. (BARTHES, 2004, p.72-75). É como se Barthes estivesse nos propondo a 
ideia de que o campo metodológico que ele se esforçou por inaugurar fosse também o de uma certa ontologia e, consequentemente, o de uma ética.

Se entendemos que o processo de constituição de singularidades é indissociável do movimento da escrita, ou pelo menos de alguma das muitas formas de criação de linguagem, então é possível pensarmos a "forma texto" como o espaço que suporta aquilo que Nancy e Blanchot entenderam como sendo a comunidade. Com efeito, é a possibilidade, pelo texto, de pensarmos um campo de coexistência das linguagens que serve para que Barthes o diferencie do domínio das obras. Ou ainda, como retomado por Nancy,

A comunidade tem necessariamente lugar no que Blanchot nomeou inoperância. Aquém ou além da obra, o que se retira da obra, o que não tem mais a ver, nem com a produçáo, nem com o acabamento, mas que encontra a interrupção, a fragmentação, o suspenso. A comunidade é feita da interrupção das singularidades, ou do suspenso que são as singularidades. (NANCY, 2016, p.63)

O livro das comunidades, de Maria Gabriela Llansol, compóe, ao lado d' A restante vida e Na casa de julho e agosto, a trilogia "Geografia de Rebeldes". Nessa geografia em que a interrupção e a fragmentação não são apenas um estilo ou um fracasso, mas a forma do escrito, Llansol traça o percurso das figuras e o espaço da textualidade. Trata-se da criaçáo de um dispositivo escrito, onde as figuras humanas podem coabitar com as figuras da sua linhagem e com outras figuras não-humanas, numa simultaneidade temporal. "Não na temporalidade da história, mas na temporalidade dos seus afectos, nas formas que revelam, nos pensamentos que sublevam, no rasto do fulgor que deixam no sentido que interrogam" (LLANSOL, 2011, p.40).

$\mathrm{Na}$ coletânea Entrevistas, Llansol apresenta a linhagem, constituída unicamente por solitários, que dá vida ao "espaço edénico", a partir do "encontro inesperado do diverso". Constituída por Eckhart, João da Cruz, as beguinas, Dickinson, Rilke, Pessoa, Nietzsche, Hölderlin, Espinosa, entre outros, ao lado dos animais e vegetais, todos eles se tornam figuras da obra, sendo aproximadas pelo fio do fulgor destacado em cada uma delas. $\mathrm{O}$ entrevistador conclui que não se pode fazer um balanço brilhante dessa linhagem, afinal "Rilke não conseguiu entrar com o seu corpo no poema", "Nietzsche enlouqueceu", "Hölderlin endoideceu". Ao que Llansol responde: "de fato não é um balanço brilhante, mas pode revelar-se um balanço cheio de ensinamentos. [...] O objetivo era o de encontrar passagem, para eles e para os outros, náo o de ficarem esfacelados e implodidos nos recifes da travessia" (LLANSOL, 2011, p.36, grifo nosso).

Nietzsche compóe o mundo figural de Llansol, atravessando a noite escura e buscando encontrar clareiras de respiração na linguagem. Retirado 
do tempo da história, em que não encontrara um lugar de hospitalidade, Llansol o acolhe no seio dessa comunidade por vir, no espaço do seu corpo textual, no ritmo de sua escrita.

Nietzsche deitado sobre o meu seio faz-me medo. O vento sopra, a lua resplandece, ó meus longínquos, longínquos filhos, porque não estais aqui? Mas hoje, ao amar tanto Nietzsche, há um obstáculo a esta evocação. O silêncio anuncia imobilidade e noite, não obscura; flutuo num ritmo de textos, o meu braço nu assente sobre a página, moreno e cheio, por envelhecer. (LLANSOL, 1999, p.64)

Ao lado de outros, Nietzsche e Llansol fundam uma "comunidade inconfessável", que reúne os "absolutamente sós", marcados que estão por uma experiência da feminilidade, do humano, do sexo e da libido que não encontra correspondência - a "nota fora das sete, da comunidade das beguinas" (LLANSOL, 2003, p.109). Llansol toma para si a responsabilidade de prosseguir numa linguagem sem apoio, pensante e de amplitude geográfica, que retira da experiência mística o erotismo e a linguagem necessários à composição dessa comunidade.

A comunidade fundada a partir da leitura da mística inclui a exterioridade que o pensamento náo controla, dando a essa exterioridade nomes distintos: a morte, a relação com outro ausente, o arrebatamento, o amor, a palavra-silente. Nela temos as dimensóes de uma geografia que não conhece fronteiras, lugar onde o disperso se reúne para formar uma unidade que é pura expansão.

Para Blanchot, a comunidade, enquanto rege, para cada um, um forade-si, uma ausência que é seu destino, dá lugar a uma palavra sem partilha e necessariamente múltipla. Sempre já perdida, sem uso e sem obra, essa palavra é a palavra do poema, a palavra poética. É ela que guarda o segredo da experiência revelada pela mística, e que não encontra correspondência na linguagem do cotidiano. E, no entanto, a palavra é o desejo de eliminar, a cada vez, aquilo que a ultrapassa e excede. O dom da palavra, "dom em pura perda”, e que náo assegura a certeza de ser acolhido pelo outro, é a súplica, ou o desespero que Nietzsche tão bem conhecia, que traz consigo o risco da rejeição. É sem dúvida neste fracasso que a comunidade acolhe a palavra, em seu desejo de "livro por vir".

Llansol ofereceu o texto, o espaço de um livro, a geografia rebelde de uma comunidade. Sem separar a escrita e a leitura, ela toma da mística o arrebatamento que conduz a uma perda de si, um desapego em relação à conservação da vida e à indiferença em relação a tudo o que tende a assegurá- 
la. Nesses estados em que se perde o poder de designar, o texto é aquilo que resta como lugar de escrita da experiência de arrebatamento. São estados marcados pelo intervalo entre a angústia da perda dos limites e o instante em que as forças do ser naufragam, conduzindo-o a uma abertura em direção a um transbordamento de alegria infinita. É nesse espaço que Llansol compóe, com Nietzsche, o seu canto:

Semivivos que me cercais, e me encerrais numa solidão subterrânea, no mutismo e no frio do túmulo; vós, que me condenais a levar uma vida que mais valia chamar morte, voltareis a ver-me, um dia. Depois de morto terei a minha vingança: sabemos voltar, nós, os prematuros. É um dos nossos segredos. Voltarei vivo, mais vivo do que nunca. (LLANSOL, 2014, p. 57)

Para Bataille, essa experiência fronteiriça entre vida e morte equivale àquela do erotismo, em que na ausência do jogo real e voluntário dos corpos, alcançam-se estados de puro êxtase. Em tais estados, dá-se a dissoluçấo das formas constituídas na transgressão do elemento de descontinuidade que garante as existências individuais. Na ruptura, é a continuidade do ser, no aberto que a experiência mística oferece, que assume a condição de uma verdade iminente.

O erotismo, como experiência que se desenrola no corpo, é a recusa da vontade de um fechamento sobre si. Nesse passo, o corpo abre-se à experiência da morte, desde que possamos entendê-la como aquilo que rompe com unidades cristalizadas que fazem sobreviver uma duração individual. A experiência do transbordamento místico - uma das versóes do erotismo - rompe a conformidade dos corpos. O que ela revela é uma ausência de objeto e o espaço aberto da pura continuidade. Os corpos se aproximam, metamorfoseiam-se, sem hierarquia nem ruptura, e esse corpo que escreve pode suscitar as coisas, traduzi-las na trama de vazio e ausência, torná-las manifestas por seu distanciamento, sem que com isso tenha que romper o vazio de sentido que o conduziu a tal experiência.

Citando Bataille, Blanchot (2013, p.37) nos diz: "a comunidade [...] é aquela que existiu virtualmente pelo fato da existência de Nietzsche (que é a exigência dela) e que cada um dos leitores de Nietzsche desfaz ao se esquivar - isto é, não resolvendo o enigma posto (não o lendo, inclusive)". O que Bataille e Llansol recolhem, no espaço de seus textos, é o desejo apoiado no vazio. Desejo trágico que permanece eternamente solitário, mas que recebe um espaço de partilha em que o enigma da "vontade de comunidade" é sustentado na gravidade de sua ilegibilidade.

Que a solitária altura não permaneça eternamente solitária e não se baste eternamente a si mesma; que o monte desça ao vale e o vento dos cumes, às 
baixadas - Oh, quem encontraria o nome certo de batismo e virtude para tal anseio! "Virtude dadivosa" - assim, um dia, denominou Zaratustra esse inominável anseio. (NIETZSCHE, 1998, p. 196)

Inominável anseio dobrado no suporte de papel, recolhido num espaço temporal recém-nascido. O livro acolhe essa "virtude dadivosa", fazendo com ela a comunidade dos "absolutamente sós" que nasce com a escrita e a soberania da partilha da solidáo. Errando à procura de uma nova paisagem, no risco dos passos que se deslocam na exterioridade radical da comunidade, a palavra de Nietzsche abre-se ao espaço da textualidade llansoliana, à sua forma tecida com rigor. Sem apagar a ausência, sem silenciar a violência sofrida pelos corpos que desejavam a travessia e sem negar a loucura, a forma que a sua escrita inaugura é: durar, continuar, não interromper. A resposta: uma "comunidade de figuras" (LLANSOL, 2004, p.72).

\section{Referências bibliográficas}

BATAILLE, Georges. O erotismo. Porto Alegre: L\&PM, 1987.

BATAILLE, Georges. Sobre Nietzsche. Trad. Fernando Scheibe. Belo Horizonte: Autêntica Editora, 2017 [1945].

BARTHES, Roland. O rumor da língua. Trad. Mario Laranjeira. São Paulo, Martins Fontes, 2004 [1984].

BLANCHOT, Maurice. O livro por vir. São Paulo: Martins Fontes, 2005.

BLANCHOT, Maurice. A comunidade inconfessável. Trad. Eclair Antônio Almeida Filho. Brasília: Editora Universidade de Brasília, 2013 [1983].

LLANSOL, Maria Gabriela. O livro das comunidades. Lisboa: Relógio D’Água, 1999.

LLANSOL, Maria Gabriela. Onde vais, Drama-Poesia? Lisboa: Relógio D’Água, 2000.

LLANSOL, Maria Gabriela. A restante vida. Lisboa: Relógio D’Água, 2001.

LLANSOL, Maria Gabriela. Na casa de julho e agosto. Lisboa: Relógio D’Água, 2003.

LLANSOL, Maria Gabriela. Contos do mal errante. Lisboa: Assírio \& Alvin, 2004.

NANCY, Jean-Luc. A comunidade inoperada. Trad. Soraya Guimarães Hoepfner. Rio de Janeiro: 7Letras, 2016 [1986].

NIETZSCHE, Friedrich. Assim falou Zaratustra. Trad. Mário da Silva. Rio de Janeiro: Bertrand Brasil, 1998 [1891]. 
Janaina Rocha de Paula é professora colaboradora do Programa de Pós-graduação em Estudos Literários da UFMG. Possui graduação em Psicologia pela Pontifícia Universidade Católica de Minas Gerais, mestrado em psicologia pela UFMG e doutorado em Estudos Literários - Literatura comparada e Teoria da literatura Linha de pesquisa: Literatura e Psicanálise - pela Faculdade de Letras da UFMG. Atua em pesquisas principalmente nos seguintes temas: teoria literária, literatura comparada, poéticas da edição e da tradução, escrita, poesia, literatura e psicanálise. E-mail: janardepaula@gmail.com

Luis Fernando Balby é doutorando em Estudos Literários - Literatura Comparada e Teoria da Literatura - linha de pesquisa: Literatura e Psicanálise - pela Faculdade de Letras da UFMG. Atua em pesquisas principalmente nos seguintes temas: teoria literária e literatura comparada. Possui mestrado em Literatura Cultura e Contemporaneidade pela PUC-Rio, e graduação em Letras - Português pela Universidade Estácio de Sá e em Relaçôes Internacionais pela UnB.

E-mail: luisbalby@gmail.com

\section{ERRATA}

https://dx.doi.org/10.1590/1517-106X/2018202105120errata

\section{No artigo}

A comunidade dos que escrevem a comunidade. Alea, v.20, n.2, p.105120, 2018. DOI 10.1590/1517-106X/2018202105120

\section{Na página 105:}

Onde se lia:

Luis Fernando Baldy

Leia-se:

Luis Fernando Balby 